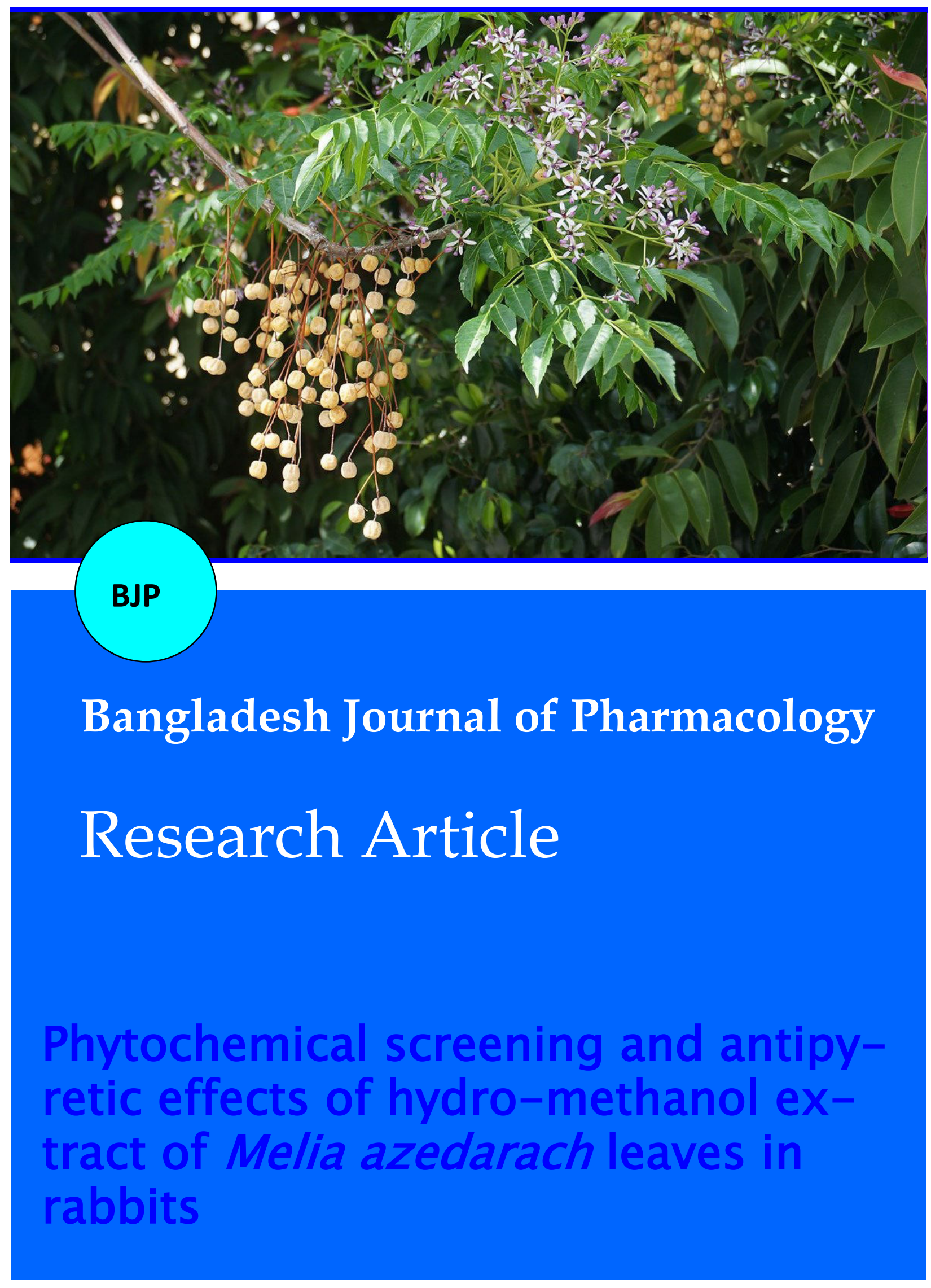


Abstracted/indexed in Academic Search Complete, Agroforestry Abstracts, Asia Journals Online, Bangladesh Journals Online, Biological Abstracts, BIOSIS Previews, CAB Abstracts, Current Abstracts, Directory of Open Access Journals, EMBASE/Excerpta Medica, Google Scholar, HINARI (WHO), International Pharmaceutical Abstracts, Open J-gate, Science Citation Index Expanded, SCOPUS and Social Sciences Citation Index

ISSN: $1991-0088$

\title{
Phytochemical screening and antipyretic effects of hydro-methanol extract of Melia azedarach leaves in rabbits
}

\author{
Sabira Sultana ${ }^{1}$, Naveed Akhtar ${ }^{1}$ and Hafiz Muhammad Asif ${ }^{2}$ \\ ${ }^{1}$ University College of Conventional Medicine, Faculty of Pharmacy and Alternative Medicine, The Islamia University \\ of Bahawalpur, Pakistan; ${ }^{2}$ Department of Eastern Medicine and Surgery, Faculty of Health \& Medical Sciences, The \\ University of Poonch, Rawalakot, AJ \& K, Pakistan.
}

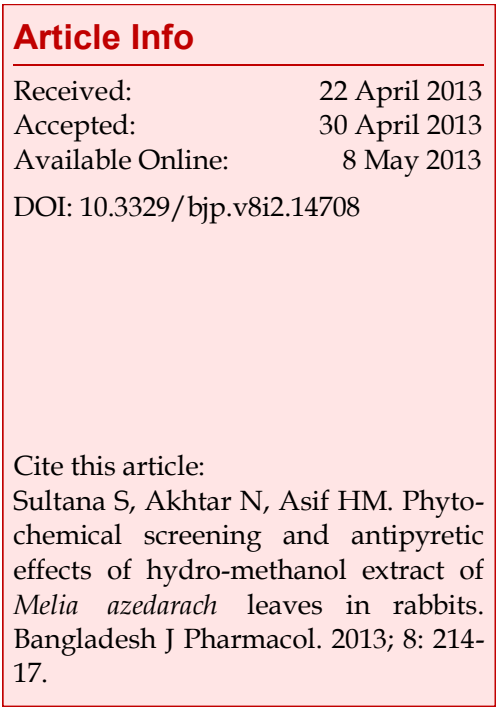

\begin{abstract}
The antipyretic effect of the hydro-methanol extract of Melia azedarach leaves was investigated using the yeast induced pyrexia method in rabbits. Paracetamol was used as a positive control and negative control group received distilled water. Rectal temperatures of all rabbits were recorded immediately before the administration of the extract or vehical or paracetamol and again at 1 hour interval for 6 hours using digital thermometer. The extract was also phytochemically screened for alkaloids, tannins, saponins, flavonoids, cardiac glycosides and phenols. At $500 \mathrm{mg} / \mathrm{kg}$ dose the extract showed significant $(\mathrm{p}<0.0001)$ reduction in yeast-induced elevated temperature as compared with that of standard drug paracetamol whereas the extract dose $250 \mathrm{mg} / \mathrm{kg}$ was less effective when compared with higher dose $(p<0.05)$. Phytochemical screening showed the presence of alkaloids, tannins, flavonoids, saponins and phenols. This study showed that the hydro-methanol extract of $M$. azedarach leaves at a dose of $500 \mathrm{mg} / \mathrm{kg}$ possesses significant antipyretic effect against the yeast-induced elevated temperature.
\end{abstract}

\section{Introduction}

Melia azedarach L. (Meliaceae) (Local name: Bakain) is a useful traditional medicinal plant like Azadirachta indica (A. indica) (Local name: Neem) from family Meliaceae. Each part of the $M$. azedarach has some medicinal properties similar to $A$. indica and thus is commercially exploitable. During the twenty year considerable progress has been achieved regarding the chemistry of the plant, biological activity and medicinal applications of M. azedarach (Khan et al., 2008).

M. azedarach is native to Tropical Asia and widely distributed in Pakistan, India, Indonesia, Southeast Asia and Australia (Kayastha, 1985). It is used extensively against intestinal worms, in skin diseases, stomach ache, nausea, vomiting and paroxysmal fever, sciatica, lumbago, piles, asthma, wounds, diabetes, post labor pain in uterus, ammenorrhoea, leucoderma (Sharma et al., 2001). Leaves of $M$. azedarach L. possess anthelmintic, diuretic, deobsturent and resolvent properties. Leaf extract $5-10 \mathrm{~mL}$ is given orally twice a day for pyrexia for seven days (Khan et al., 2002).

Variety of chemical constituents have been detected in $M$. azedarach leaf including kampherol, quercetin, stigmasterol, $\beta$-sitosterol, campesterol, phytol, beta-carotene, tocopherol and squalene, 1-eicosanol (Sen et al., 2012).

Leaves of $M$. azedarch have been scientifically reported to exert hepatoprotective (Ahmed et al., 2012), antioxidant (Munir et al., 2012), antimalirial (Charturvedi et al., 2006) activities.

Seeds of $M$. azedarach possess antimalarial, antifungal (Carpinella et al., 2005), anti-fertility activities (Mandal 
et al., 2007). Root bark of M. azedarach exhibited cytotoxicity activity against lymphocytic leukemia P388 cell lines in vitro (Itokawa et al., 1995).

Thus, as the experimental plant species $M$. azedarach possesses immense medicinal properties, yet the plant has not been investigated for its antipyretic activity on the scientific base. Therefore, the aim of the present study is to identify its antipyretic activity using the hydro-methanolic leaf extract.

\section{Material and Method}

Animals used: In this study adult healthy rabbits weighing 1,000-1,200 $\mathrm{g}$ of either sex were obtained from laboratory animal center, The Islamia University Bahawalpur. All the animals were maintained in air conditioned animal house located in the faculty of Pharmacy and Alternative Medicine, The Islamia University Bahawalpur. They were fed with standard pellet diet. The animals were acclimatized in an environment of controlled temperature $22-25^{\circ} \mathrm{C}$ and 12 hours light/ dark cycle for five days prior to study. All the animals were fasted one hour before drug treatment. Food and water were continued after the administration of drug.

Plant material: The leaves of $M$. azedarach were collected from Bahawalpur City during the month of March, 2012 and were identified by Dr. Shazia Anjum, Director, Cholistan Institute of Desert Studies, at the Islamia University of Bahawalpur. The voucher specimen (3412/ CIDS/IUB) was deposited in the herbarium of the CIDS, The Islamia University of Bahawalpur.

Preparation of extract: The fresh green leaves of $M$. azedarach were separated and cleaned and washed with distilled water and dried under shade at temperature between $21-30^{\circ} \mathrm{C}$ for 30 days. $1,000 \mathrm{~g}$ of powdered material of $M$. azedarach leaves was taken in beaker having $5 \mathrm{~L}$ capacities and $2 \mathrm{~L}$ of $70 \%$ methanol was added, soaked for 72 hours with occasional shaking and stirring. The residues were extracted thrice with the same fresh solvent and extract combined. The soaked material of plant was filtered through several layers of muslin cloth one by one for coarse filtration. The filtrate was filtered through a Whatman \# 1 filter paper. The filtered extracts were concentrated under reduced pressure at $40^{\circ} \mathrm{C}$, in rotary evaporator. The semi-solid mass was obtained and was weighed to calculate the yield, which was $29.4 \%(\mathrm{w} / \mathrm{w})$ and stored in a refrigerator $\left(-8^{\circ}\right.$ C), until used for analysis.

Drug, reagents and test agents: Paracetamol (Islamia University Bahawalpur, Pakistan; GlaxoSmithKline, Pakistan, Limited), methanol (Merk KGaA Darmastadt, Germany), normal saline (Siza International Lahore, Pakistan), distilled water (Department of Pharmacy, IUB, Pakistan), baker yeast (Rossmoor food products, Karachi, Pakistan).
Phytochemical screening: The hydro-methanol extract of $M$. azedarach leaves was subjected to standard phytochemical screening for flavonoids (sodium hydroxide, ferric chloride and lead acetate test), alkaloids (Dragondroff,s and Mayer's test), tannins (ferric chloride test), saponins (foam test) as described by (Harborne, 1973). Phenols (Ferric chloride test), cardiac glycosides (Chloroform and sulphuric acid test) described by (Rasool et al., 2010; Sofowora, 1993) respectively.

Antipyretic activity (yeast-induced pyrexia method): Antipyretic activity was performed by slightly modifying the method described by (Bose et al., 2007). Rabbits of either sex weighing 1,000-1,200 g were divided into four groups of six rabbits in each group. The rectal temperature of all the rabbits was measured with digital thermometer before the administration of yeast suspension. Pyrexia was induced by subcutaneously injecting $3 \mathrm{~mL} / \mathrm{kg} /$ body weight of $10 \% \mathrm{w} / \mathrm{v}$ yeast suspension in the back of the rabbits. After the 18 hours, of the administration of yeast suspension temperature was measured. The rabbits showed 0.5 to $1.5^{\circ} \mathrm{C}$ increase in temperature were selected for the study. Group I is negative control and received distilled water. Paracetamol at a dose of $150 \mathrm{mg} / \mathrm{kg}$ body weight was given orally to positive control Group II. Plant extract at a dose of 250 and $500 \mathrm{mg} / \mathrm{kg}$ body weight were administered to group III and group IV respectively. The rectal temperature was recorded at the interval of one hour for 6 hours.

Statistical analysis: The data obtained were analyzed statistically using SPSS17.0. The tool used for this purpose was one-way analysis of Variance (ANOVA) followed by LSD post-hoc test for multiple comparisons.

\section{Results}

The preliminary phytochemical screening of the hydromethanol extract of $M$. azedarach leaves gave positive test for alkaloids $(+++)$, flavonoids $(+++)$, saponins $(+++)$, tannins $(++)$ and phenols $(+)$.

Result with regard to the antipyretic effect of the hydromethanol extract of $M$. azedarach leaves in the pyrexic rabbits given in Table I. Basal rectal temperature of rabbits before injection of the suspension of baker yeast in negative control group was $38.4 \pm 0.1$, in positive control group was $38.4 \pm 0.1$. In the plant extract 250 $\mathrm{mg} / \mathrm{kg}$ of treatment group, the rectal temperature was $38.6 \pm 0.2$ and in $500 \mathrm{mg} / \mathrm{kg}$ of treatment group, the rectal temperature was $38.6 \pm 0.1$. Administration of baker yeast produced an increase in temperature after 18 hours. The rectal temperature recorded in the negative control group was $40.1 \pm 0.0$ and in positive control group was $40.1 \pm 0.0$. The rectal temperature in the treatment groups $250 \mathrm{mg} / \mathrm{kg}$ was $40.1 \pm 0.0$, and 


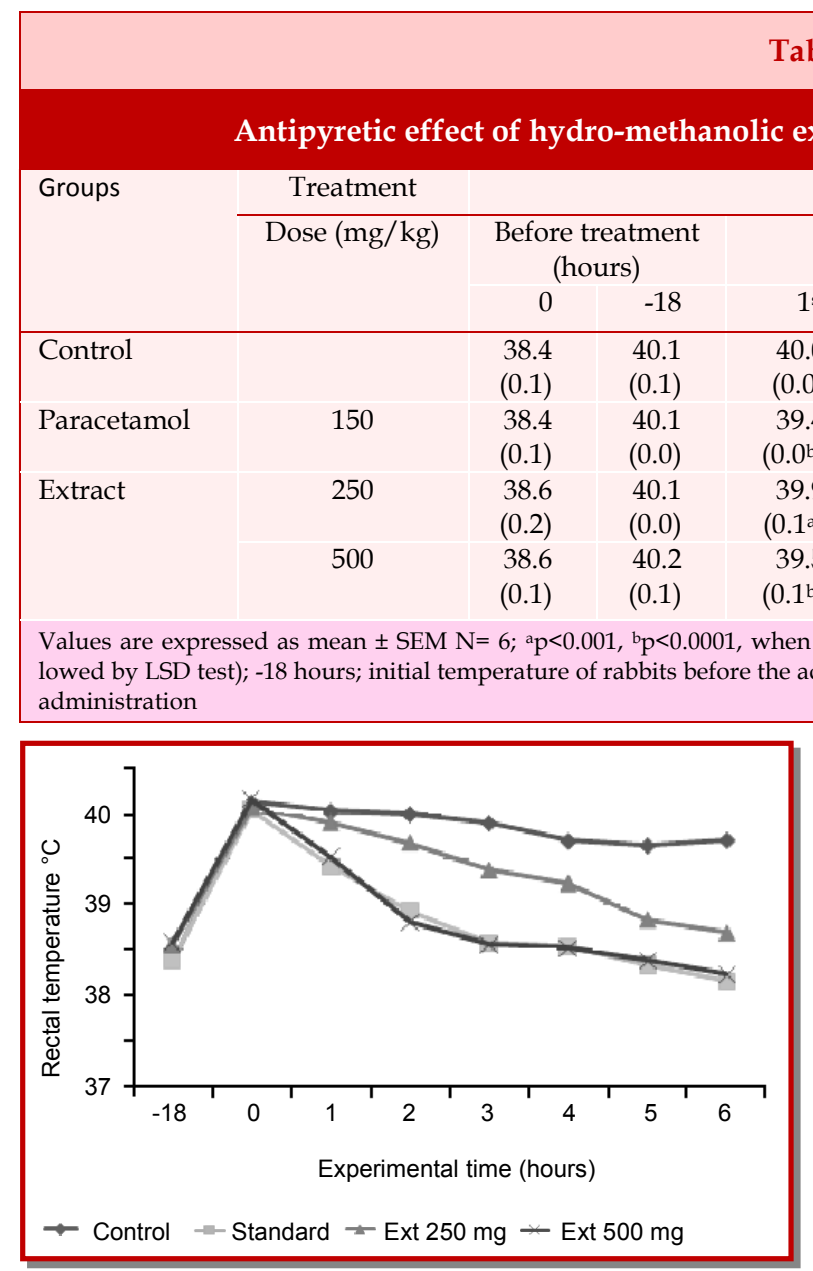

Figure I: Antipyretic effect of hydro-methanol extract of $M$. azedarach leaves (250 and $500 \mathrm{mg} / \mathrm{kg}$ p.o) in rabbits; $-18=$ Temperature just before yeast injection; $0=$ Temperature just before drug administration

was $40.2 \pm 0.1 \mathrm{in} 500 \mathrm{mg} / \mathrm{kg}$ treatment group.

The administration of hydro-methanol extract of $M$. azedarach $(250 \mathrm{mg} / \mathrm{kg}$ and $500 \mathrm{mg} / \mathrm{kg})$ and paracetamol reduced the body temperature to $38.6 \pm 0.1,38.6 \pm 0.1$ and $39.4 \pm 0.1$ respectively after 3 hours. Hydromethanol extract of $500 \mathrm{mg} / \mathrm{kg}$ showed significant $(\mathrm{p}<0.0001)$ anti-pyretic activity compare to control. The effect was similar to that of standard drug paracetamol. The extract dose $250 \mathrm{mg} / \mathrm{kg}$ also reduced the temperature but the effect was slow compare to higher dose. After 6 hours temperature remain unchanged at $38.7 \pm$ 0.1 and $38.2 \pm 0.1$ in the extract treated groups (250 and $500 \mathrm{mg} / \mathrm{kg}$ ) respectively.

\section{Discussion}

Fever or pyrexia is a complex physiologic process characterized by elevated body temperature above normal range. Body temperature is regulated by a temperature regulating centre present in the hypothalamus. Hypo-

Table I

extract of Melia azedarach leaves in rabbits

\begin{tabular}{|c|c|c|c|c|}
\hline \multicolumn{5}{|c|}{ After treatment (hours) } \\
\hline $2^{\text {nd }}$ & $3^{\text {rd }}$ & $4^{\text {th }}$ & $5^{\text {th }}$ & $6^{\text {th }}$ \\
\hline 40.0 & 39.9 & 39.7 & 39.7 & 39.7 \\
\hline$(0.0)$ & $(0.0)$ & (0.1) & (0.1) & (0.1) \\
\hline 38.9 & 38.6 & 38.5 & 38.3 & 38.2 \\
\hline$\left(0.0^{\mathrm{b}}\right)$ & $\left(0.1^{b}\right)$ & $\left(0.1^{b}\right)$ & $\left(0.0^{\mathrm{b}}\right)$ & $\left(0.0^{\mathrm{b}}\right)$ \\
\hline 39.7 & 39.4 & 39.2 & 38.8 & 38.7 \\
\hline$(0.1)$ & $(0.1)$ & $(0.1)$ & $\left(0.1^{b}\right)$ & $\left(0.1^{b}\right)$ \\
\hline 38.8 & 38.6 & 38.5 & 38.4 & 38.2 \\
\hline$\left(0.2^{b}\right)$ & $\left(0.1^{b}\right)$ & $\left(0.1^{b}\right)$ & $\left(0.1^{b}\right)$ & $\left(0.1^{b}\right)$ \\
\hline
\end{tabular}

compared with the control value of corresponding hours (ANOVA folmistration of yeast suspension 0 hour; temperature at the time of drug thalamus ensures a balance between heat loss and heat production. Fever happens when there is the disturbance of this regulatory centre that leads to the set point of body temperature being raised (Rang et al., 1992).

When any pyrogen is injected into the hypothalamus of the experimental animals, fever which is not blocked by systemic salicylates, develops within a few minutes of administration of nanogram amount (Milton and Wendlandt, 1971) in their report proposed that prostaglandin acts as a molecular transmitter of pyrogenic stimuli in the hypothalamus. Abramson and Weissmann (1989) and Coelho et al. (1995) therefore proposed that nonsteroidal anti-inflammatory drugs and glucocorticoids, reduce the elevated temperature during febrile response by inhibiting the biosynthesis of prostaglandins and inhibition of plasma prostaglandin level. Their findings therefore confirmed the earlier views of Milton and Wendlandt, 1971.

Non-steroidal anti-inflammatory drugs NSAIDs like acetylsalicylic acid exert their antipyretic action by inhibiting prostaglandin synthesis (E-type) in the hypothalamus (Rang et al., 1992). As a result elevated plasma prostaglandin level, as observed in fever is suppressed. Paracetamol, the reference antipyretic drug used in this study also has same effect by a selective action on a specific cyclooxygenase (COX) iso enzyme in the CNS (Flower and Vane, 1972).

The hydro-methanol leaf extract of $M$. azedarach demonstrated marked antipyretic activity as evident in the inhibition of temperature elevation in the yeast model. Therefore, the antipyretic action of extract may be, due to the inhibition of prostaglandin synthesis, leading to the suppression of elevated plasma level, especially since the extract had been shown to possess anti-inflammatory activities (Sidaye et al., 2011).

The result of phytochemical screening of hydromethanol extract of $M$. azedarach leaves showed that it contains tannins, alkaloids, flavonids, phenols and 
saponins while extract is negative for cardiac glycosides. It is shown by the previous studies of phytochemical analysis of different parts of $M$. azedarach that plant contains 96 terpenoids and limonoids; 5 flavonoids; 14 steroids; 7 carboxylic acid and 3 antharaquiones (Kumar et al., 2003).

Preliminary phytochemical study indicated that extract contains alkaloids, tannins, flavonoids, phenolic compounds and any one of which may be responsible for the antipyretic activity of these plants. Alkaloids like bolidine have the ability to reduce the elevated temperature by inhibiting the prostaglandin E2 synthesis (Backhouse et al., 1994). Similarly, flavonoids like baicalin possess antipyretic effect by suppressing TNF-a (Chang et al., 2007). One of the compounds pyrozol-5 $(2 \mathrm{H})$-one ( $0.26 \%$-flavonoids) isolated $M$. azedarach leaves possessed wide spectrum of biological activities such as anti-inflammatory, antipyretic and analgesic (Sidaye et al., 2011). Therefore, antipyretic activity might be due to the flavonoids and or the alkaloidal components of the plants extracts. It is concluded that the hydro-methanol extract of $M$. azedarach leaves, possesses highly significant antipyretic effect .

\section{Acknowledgement}

The authors are thankful to the Dean and the Chairman of the University College of Conventional Medicine, Faculty of Pharmacy and Alternative Medicine, The Islamia University of Bahawalpur for providing support and necessary facilities to carry out this work successfully.

\section{References}

Abramson S, Weissmann G. The mechanisms of action of nonsteroidal anti-inflammatory drug. Clin Exp Rheumatol. 1989; 3: 163-70.

Ahmed MF, Rao AS, Ahemad SR, Ibrahim M. Phytochemical studies and hepatoprotective activity of Melia azedarach Linn, against $\mathrm{CCl}_{4}$ induced hepatotoxicity in rats. J Pharm Res. 2012; 5: 2664-67.

Antara S, Amla B. Chemical composition of methanol extract of the leaves of Melia azedarach L. Asian J Pharmaceut Clin Res. 2012; 5: 42-45.

Bose A, Mondal S, Gupta JK, Gosh T, Dash GK, Sudam S. Analgesic, anti-inflammatory and anti-pyretic activities of the ethanolic extract and its fraction of Cleome rutidosperma. Fitoterpia 2007; 78: 515-20.

Backhouse N, Delporte C, Givernau M, Cassels B, Valenzuela A, Speisky H. Anti-inflammatory and anti-pyretic effects of boldine. Inflam Res. 1994; 42: 114-17.

Chang $\mathrm{CP}$, Huang WT, Cheng BC, Hsu CC, Lin MT. The flavonoid baicalin protect again cerebrovascular dysfunction and brain inflammation in experimental heatstroke. Neuropharmacology 2007; 52: 1024-33.

Charturvedi, Raseroka P, Ntshebe BH. Antimalarial activity of
Melia azedarach. J Appl Zool Res. 2006; 1: 109-13.

Itokawa H, Qiao ZS, Hirobe C, Takeya K. Cytotoxic limonoids and tetranortriterpenoids from Melia azedarach. Chem Pharm Bull. 1995; 43: 1171-75.

Coelho MM, Luheshi G, Hopkins NJ, Rothwell. Multiple mechanism mediate antipyretic action of glucocorticoids. Am J Physiol. 1995; 269: 527-35.

Carpinella MC, Ferrayolic CG, Palacios SM. Antifungal synergistic effect of scopoletin, a hydroxycoumarin isolated from Melia azedarach L. fruits. J Agric Food Chem. 2005; 53: 292227.

Flower RJ, Vane JR. Inhibition of prostaglandin synthetase in brain explains the anti-pyretic activity of paracetamol (4acetamidophenol). Nature 1972; 240: 410-11.

Harborne JB. Phytochemical methods. London, Chapman and Hall Ltd., 1973, pp 49-188.

Kumar R, Singh R, Meera RS, Kalidhar SB. Chemical components and insectisidal properties of Bakyain (Melia azedarach L.): A Review. Agric Rev. 2003; 24: 101-15.

Kayastha BP. Silvics of the trees of Nepal. Community forest development project, Kathmandu, 1985.

Khan AV. Ethanobotanical studies on plants with medicinal plants with medicinal and antibacterial properties. Aligarh, Aligarh Muslim University, 2002, pp 1-293.

Khan AV, Khan AA, Shukla I. In vitro antibacterial potential of Melia azedarach crude leaf extracts against some human pathogenic bacterial strains. Ethnobot Leaf. 2008; 12: 39-45.

Milton AS, Wendlandt S. Effects on body temperature of prostaglandins of $\mathrm{A}, \mathrm{E}$ and $\mathrm{F}$ series on injection in to the third ventricle of an anaesthetized cats and rabbits. J Physiol. 1971; 218: 325-36.

Munir A, Sultana B, Babar T, Bashir A, Amjad M, Hassan Q. Investigation on the anti-oxidant activity of leaves, fruit and stem bark of Dhraik (Melia azedarach). Eur J Appl Sci. 2012; 4: 47-51.

Rang HP, Dale MM, Ritter JM. Ant-inflammatory and immune -suppressent drugs. In: Pharmacology. $4^{\text {th }}$ ed. Edinburgh. Churchill Livingstone, 1992, pp 229-47.

Rasool R, Ganai BA, Akbar S, Kamili AN, Masood A. Phytochemical screening of Prunella vulgaris L. important medicinal plants of Kashmir. Pak J Pharm Sci. 2010; $23: 4$.

Sofowora A. Medicinal plants and traditional medicine in Africa. Nigeria, Spectrum Books Ltd, 1993, p 289.

Sidaye RV, Dhanawade AE, Mansha K, Aishwarya G. Synthesis, anti-microbial and antimycobacterial activity of nicotinic-acid hydrazide derivatives. Curr Pharma Res. 2011; 1: 135-39.

Sharma PC, Yelne MB, Dennis TJ. Data base on medicinal plants used in Ayurveda, Documentation and Publication Division, Central Council for Research in Ayurveda and Siddha, New Delhi, 2001, pp 389-406.

Author Info

Sabira Sultana (Principal contact)

I e-mail: drsabirachishti12@gmail.com 